\title{
Time geography: a model for psychiatric life charting?
}

\author{
C. SUNNQVIST ${ }^{1}$ R N M c, U.PERSSON ${ }^{2}$ B A, B. LENNTOR P ${ }^{3}$ Ph D
}

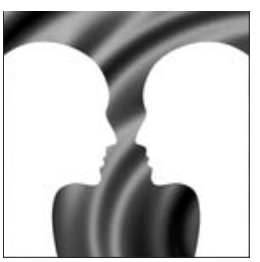

$\&$ L. TR ÄSKMAN-BENDZ ${ }^{4}$ M D P P D

${ }^{1}$ Research Nurse, ${ }^{2}$ Research Assistant, ${ }^{4}$ Professor, Department of Clinical Sciences, Psychiatry, Lund University

Hospital, Lund, and ${ }^{3}$ Professor, Department of Human Geography, Stockholm University, Stockholm, Sweden

Correspondence:

C. Sunnqvist

Department of Clinical Sciences

Psychiatry

Kioskgatan 19

Lund University Hospital, $S$ -

22185 Lund

Sweden

E-mail: charlotta.sunnqvist@

med.lu.se

\author{
SUNNQVIST C., PERSSON U., LENNTORP B. \& TRÄSKMAN-BENDZ L. (2007) \\ Journal of Psychiatric and Mental Health Nursing 14, 250-257 \\ Time geography: a model for psychiatric life charting?
}

Since many years, life charting has been used to describe the life course and life events of psychiatric patients. The aim of the present study was to describe and evaluate time geographic life charts of 11 former psychiatric patients in order to promote systematic descriptions of their life events over time. Information on all events which was gathered from the life charts was analysed by manifest content analysis and reduced to four categories: information received by asking only about moves, social capacity, predisposing life events and/or stressful as well as precipitating life events. Our findings showed that this kind of life charts offered a comprehensive and structured picture. They describe a detailed life situation from one time period to another, where geographical sites serve as anchors. The patients expressed satisfaction with this method of combining an interview with a time geographic life line.

Keywords: geographic moves, life events, manifest content analysis, social events, stressful events, time geographic life charts

Accepted for publication: 16 January 2007

\section{Introduction}

Life charting has been used for many years to describe the life course and life events of psychiatric patients. Kraepelin (1921) and Meyer (1948) used this method to follow stressful events and illness episodes of psychiatric patients over time. Ehnvall \& Ågren (2002) used the procedure suggested by Post (Roy-Byrne et al. 1985) to organize clinical information, and to investigate sensitization patterns of patients suffering from a treatment-refractory affective disorder.

Time geography, a model suggested by e.g. Hägerstrand (1991), could possibly be used for life charting of psychiatric patients. Time geography can briefly be characterized as an approach especially pertaining to social studies aimed at analysing the interaction of processes in time and space and to connect knowledge from different fields (Lenntorp
1992). The time geography approach sets time and space in focus and applies a conceptual apparatus elucidating people's lives (Kjellman 2003).

In order to recall events, autobiographical memories must be activated. An autobiographical memory contains information concerning: self-description, specific events and general events (Conway \& Bekerian 1987). The time geographic life-charting method is also supposed to activate memory using the geographic sites for household moves as anchors for memories. Moving is a significant event in life. Depending on the reason for moving and the geographical distance, essential adjustment problems might appear.

The purpose of psychiatric care is to promote mental and physical health and to increase life quality. The implication is to help the patient to see and understand her or his needs and problems, and to take care of the individual's 
own capacity in order to encourage a positive change. Psychiatric nursing is built on a nurse and patient relationship (Peplau 1952, Lego 1980).

The essential idea is that patients' life histories are of primary interest for diagnosis, care and treatment. The time geographic life line is supposed to indicate both positive and stressful life events, and therefore it may contribute to seeing and understanding the patient's current life situation.

The aim of the present study was to evaluate the possible use of time geographic life charts in clinical psychiatric practice.

\section{Materials and methods}

\section{Materials}

Eleven patients were randomly selected from a recently performed 12-year follow up study of 42 patients hospitalized after a suicide attempt and 22 matched control patients. Six of the patients who accepted to participate in this study had been inpatients after a suicide attempt, and five had been inpatients without a history of suicide attempt(s). In this study, all 11 patients are presented as former psychiatric patients regardless of suicidal behaviour.

Information on the participating subjects is given in Table 1.

\section{Methods}

\section{Follow-up interviews}

In the original comprehensive follow-up study, semistructured interviews contained information on geographic

Table 1

Characteristics of participating subjects $(n=11)$

\begin{tabular}{lll}
\hline Age (years) & Average age & $44 \pm 7$ years \\
& Age group & Number \\
& $35-44$ & 4 \\
\multirow{4}{*}{ Sex } & $45-54$ & 5 \\
\multirow{4}{*}{ Index diagnosis } & $55-64$ & 2 \\
& Women & 5 \\
& Men & 6 \\
& Major depression & 3 \\
& Dysthymia & 2 \\
& Alcohol abuse & 1 \\
& Depressive disorder NOS & 1 \\
& Obsessive-compulsive disorder & 1 \\
Civil status & Schizoaffective disorder & 1 \\
& Bipolar disorder & 1 \\
& Adjustment disorder & 1 \\
& Married/cohabiting & 5 \\
& Single & 6 \\
& University degree & 6 \\
& Upper secondary degree & 5 \\
\hline
\end{tabular}

moves throughout life; childhood-, adolescence- and adulthood conditions, education, social situations, somatic and psychic health, and also treatments and hospitalizations. The interviews focused on four time intervals: ages 0-12 years, 13-19 years, 20 - age of index hospitalization, and the time period after index hospitalization until the actual interview, which took place during the year 2002 or 2003. It was from data gathered in these follow-up interviews that the first author made the original time geographic life charts on a computer for the present study.

\section{Evaluation interviews of 11 time geographic life charts}

The evaluations, made by the main investigator (the first author), were divided into four fields of interest: geographic moves, social events, stressful events, and finally, the life line where social and stressful events were combined. An interview guide was used, covering questions about moving, social and stressful events, and how the participants felt about the events. Finally, they gave their opinion about the method. Each interview lasted approximately $2 \mathrm{~h}$ (range 1.5-3.5 h) and took place at our research centre. A research assistant (the second author), who was present at each interview session, documented the life-chart story.

\section{The process of the evaluation interview}

The evaluation (Fig. 1) started by going through the patients' geographic moves and reasons for moving, chronologically.

After this, we discussed significant social events while living in each geographical site (Fig. 2).

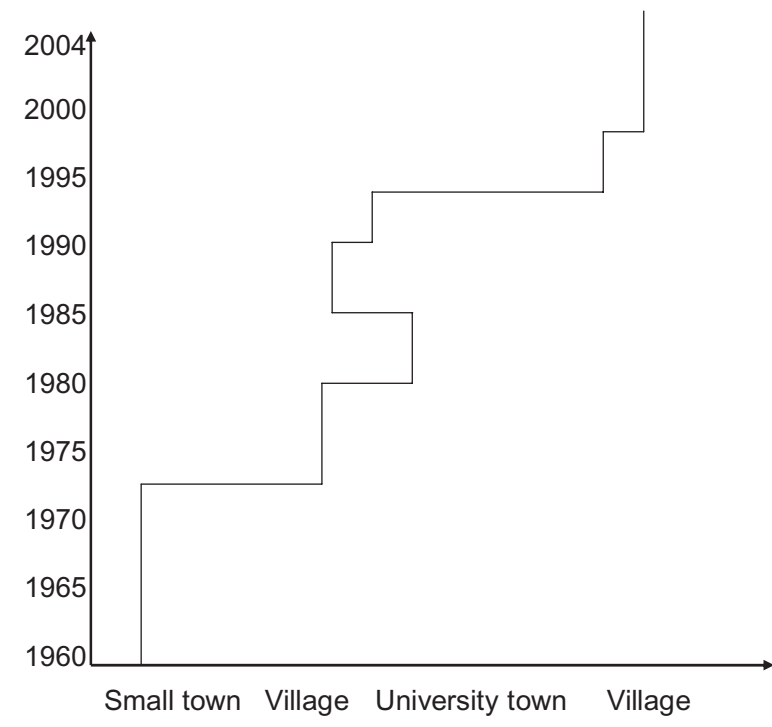

Figure 1

Geographic moves 


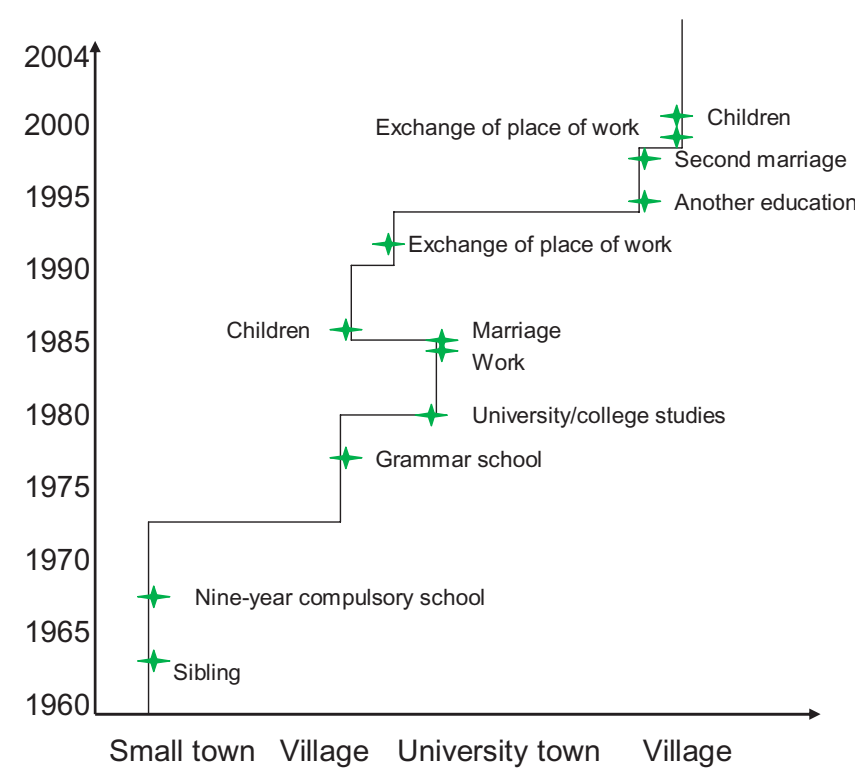

Figure 2

Social events

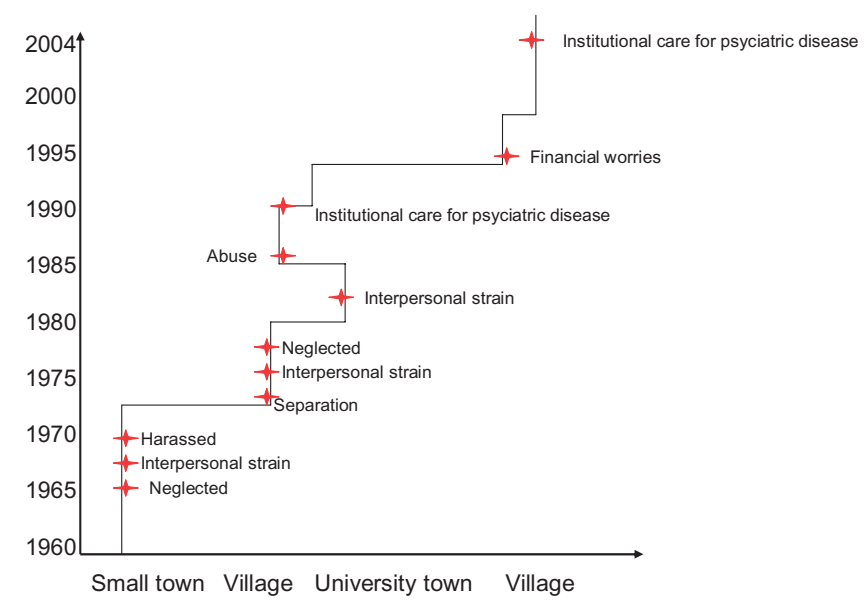

Figure 3

Stressful events

Then we discussed stressful events chronologically, and how the respective event affected the patients (Fig. 3).

Finally, the patients saw the comprehensive life line with both social and stressful life events connected to geographic moves, and were offered to express their emotions. At this stage, we also discussed the patients' opinions concerning our approach by use of time geographic life lines (Fig. 4).

\section{Arranging data}

After completion of the evaluation, the main investigator and the research assistant corrected the life line according to the new information that had just been retrieved. The research assistant wrote a life-chart summary of each participant based on the information from the time geographic

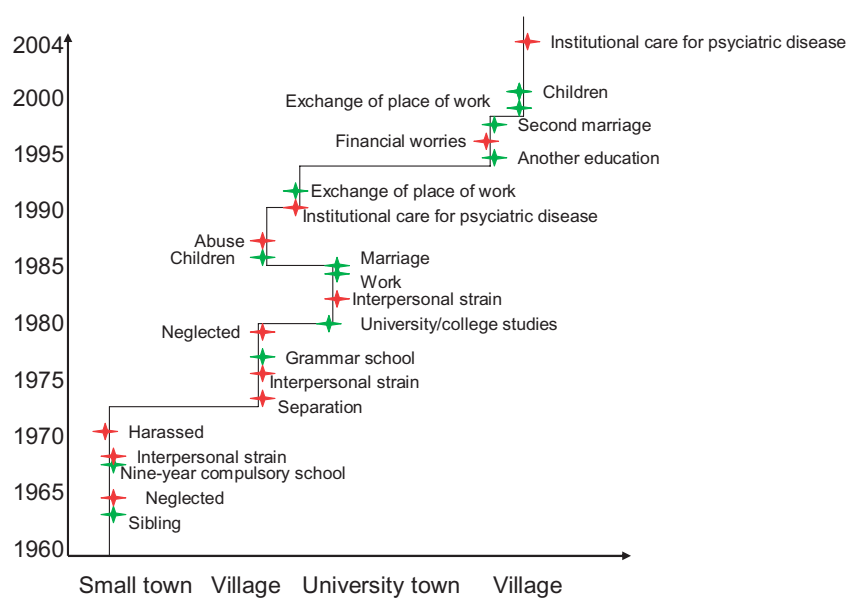

Figure 4

Comprehensive life line

life chart and the evaluation interview. All events which were gained from the time geographic life charts were analysed by manifest content analysis (Berg 1998). The analysis was made in three stages (Burnard 1996). In the first stage, all participants' events were noted by the main investigator and the research assistant (first and second authors). In the next stage, the events were gathered into subcategories, and this was performed by the first and second authors independently. After this they, together, established the subcategories, and all events belonging to each subcategory were counted. In the final stage, each subcategory was reduced to a category. In the results section, each category is described in the same and only constructed case.

The participants' perceptions and benefits of the time geographic life-chart model are narrative descriptions made by the first and second author after the evaluation interviews which were based on the follow-up interviews.

\section{Ethical considerations}

The Research Ethics Committee of the Medical Faculty of the Lund University approved this study, and all participants gave written informed consent (LU81-01).

\section{Results}

Time geographic life charts had thus already been drawn according to information retrieved from the original semistructured follow-up interview, and all participants were interested to see how we had interpreted their life history. They were satisfied to understand that they could correct possible misunderstandings. All of them had previously 
Table 2

All corrections

\begin{tabular}{lccc}
\hline & Geographic moves & Social events & Stressful events \\
\hline Corrections & $20(n=9)$ & $8(n=4)$ & $9(n=7)$ \\
New information & $2(n=2)$ & $24(n=9)$ & $23(n=10)$ \\
Misunderstandings & $1(n=1)$ & $3(n=2)$ & $7(n=4)$ \\
\hline
\end{tabular}

$n$, number of participants.

reported a lot of stressful events, but still more events were added during the evaluation, and some corrections had to be made (Table 2).

There were time corrections as well as geographic corrections. The geographic corrections usually included moving within the same area. The additional social and stressful events included such essential information as new relations, further education, childbirth, changed working situation and death of a relative, separations, maltreatment, a stressful school situation, a stressful moving of household, respectively. Some of the originally mentioned events had to be deleted, because they were not experienced as stressful. Misunderstandings concerning previously gathered information which dealt with actual time periods of stressful events were corrected and the accurate chronology could still be saved.

\section{All events gained from the time geographic life charts}

The analysis showed that the time geographic life-chart model offered: a lot of information only by asking about moves, but also information on the person's social capacity, as well as information on predisposing, stressful or precipitating life events ( Table 3 ).

In the following constructed case, all events were reduced to four categories.

\section{The constructed case}

Information received by asking only by moves (Fig. 1)

A man born in a small town in Scania, Sweden. He lived in the same town until he was 13 years old. Then he moved to a village some kilometres away because of his parents' divorce. He thought the situation was stressful, as he moved from his friends, school and father. In the new village, he lived for 7 years, and then he moved to a university town fairly near the village. This was very exiting, and he lived there for 5 years. During this period, he met a young woman, and soon they got married. A few months later, they needed a larger place to live in, because they expected a child, so they moved back to the village. He lived in this village five more years but had to move again because of a divorce. This event was very stressful, and he was admitted to institutional care because of suicidal ideation. After 4 years, he moved to another village because of financial problems. In this village, he met another woman, and after a few years they bought a big house.

\section{Social capacity (Fig. 2)}

This man grew up with his mother, father and one sibling until he was 13 years old and then his parents divorced. During his childhood, he had some troubles making friends, but this ended after moving to another village. His school attendance was good and later he got a university education. He was married twice and got two children. $\mathrm{He}$ is still working and lives together with wife and children.

Predisposing life events (Fig. 3)

During ages 0-19 years, he experienced some stressful events. He felt neglected by his parents, because they treated him differently than his sibling, and he was exposed to maltreatment. He describes himself as a lively boy, who was easily frustrated and angry when he did not get what he wanted. He had a few friends, and some of his classmates harassed him at school. When he was 13 years old, his parents separated, and he had to move. This became, after all, a positive change in his life. He entered a new school and made more friends than before. However, he still felt neglected by his parents. He did not see his father very much, and his mother had plenty to do with household, work and his sibling.

\section{Stressful and precipitating life events (Fig. 3)}

When he moved to the university town he felt, at first, comfortable with the new situation and thought that life was both interesting and exciting. Unfortunately, this situation resulted in over-consumption of alcohol, anxiety and bad self-confidence. After a while, his girlfriend got tired of him and left him. He felt abandoned and started to isolate himself. In spite of this, he passed his exams, and then he obtained a good job. He had high ambitions at work, but still a lot of personal problems. He over-consumed alcohol, and suffered from insomnia, anxiety, suicidal thoughts and felt depressed. After a while, he met a woman and married her. The couple moved to another village, and their first child was born. He changed workplace, but unfortunately 
Table 3

All events through manifest content analysis

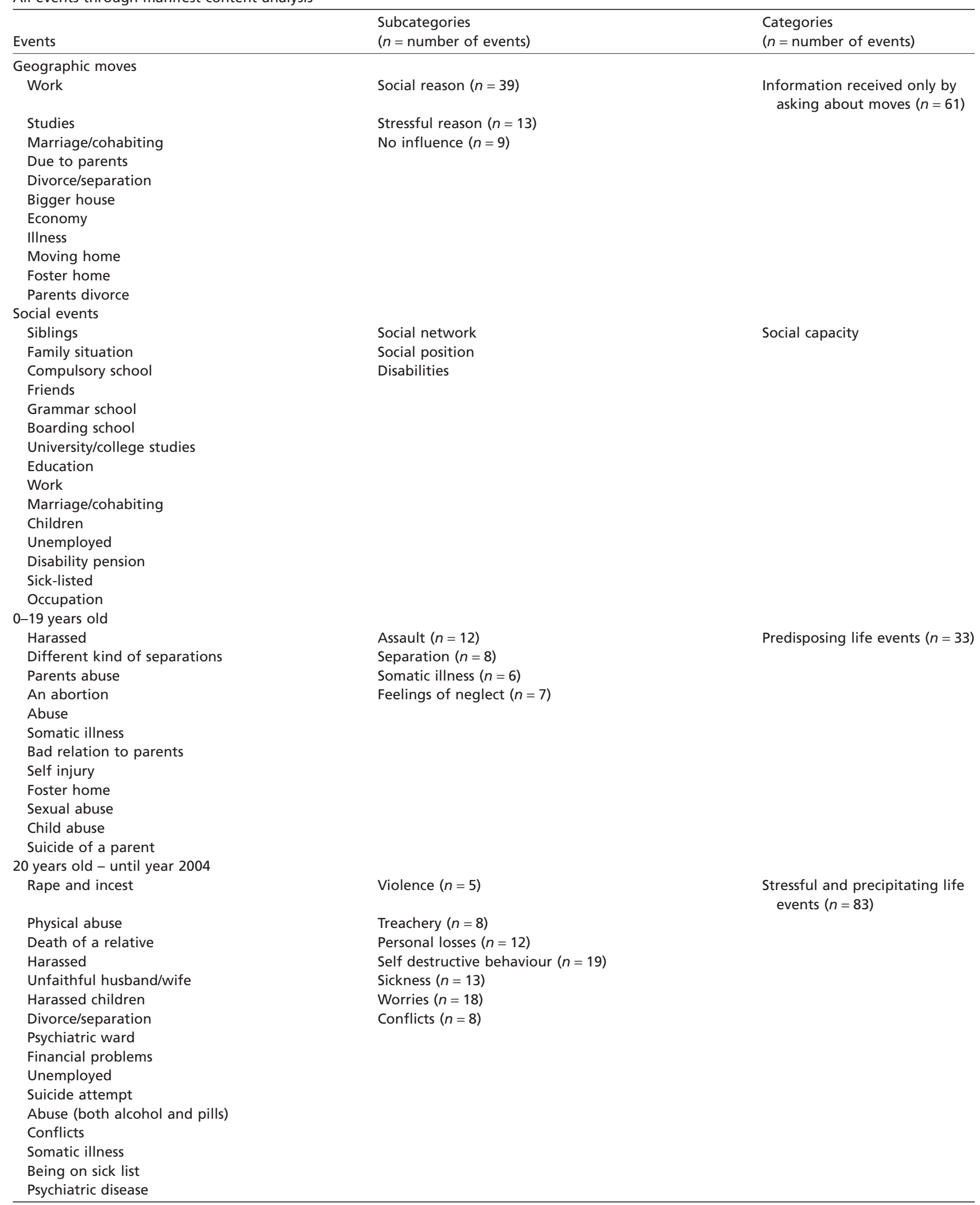


he had problems collaborating with his colleagues. Again he got symptoms such as insomnia and anxiety. He also began drinking too much alcohol and took tranquillizers every day. His problems accumulated and his wife left him. After this, he was admitted to inpatient treatment at a psychiatric clinic. After this episode, he went back to work. Yet, he was not satisfied and therefore moved to another village. Unfortunately, he ran into financial difficulties because of an expensive house, divorce and alimony for his child. After a few years, he met a new woman, remarried, and his second child was born. He applied for a new duty at work and moved again, for the sixth time during his life. It is during this period of his life that we together evaluated his geographic life chart.

\section{The patients' perceptions and benefits of the time geographic life-chart model}

\section{Patient 1}

After several years with stressful events such as suicide attempts, abuse of alcohol and tranquillisers, the patient has returned to a gainfully employed life. He thought the time geographic method was positive because he thought it was important to recall and discuss social and stressful events in order to get a comprehensive picture of the entire life situation.

\section{Patient 2}

After several years on the sick list and several suicide attempts and self-injuries, the patient is now working again. She is today free from psychiatric treatment. She thought the method could be of relevance to use in psychiatric care, because the comprehensive picture shows the whole life situation.

\section{Patient 3}

The patient has been long-term on the sick list and she has made several self-injuries and suicide attempts. She grew up under severe circumstances and her childhood was traumatic. She was positive to the method and thought that if this had been performed earlier in life, she might have received better help from the psychiatric clinic.

\section{Patient 4}

A single employed woman who has been hospitalized several times for suicide attempts and alcohol abuse. She was hesitant about the method, but thought it was important to include understanding of background processes in psychiatric treatment.

\section{Patient 5}

A man with disability pension, and a chronic psychiatric disease. He felt satisfied after we had gone through his life chart, because he thought he, better than before, could survey his situation. He also thought the method could have been a valuable tool to understand and solve his problems.

\section{Patient 6}

A divorced man with children. He was treated after a suicide attempt 10 years ago. He thought the method was very positive, because he could see his situation more clearly.

\section{Patient 7}

A divorced man, with disability pension and children, was treated for a long time because of stressful events. He thought it was valuable to discuss each event chronologically and he underlined the importance of discussing with someone who is paying attention.

\section{Patient 8}

A married woman with four children. She has a background with several stressful events, leading to inpatient care. She thought that life was hard work, but she has made it, so far. She thought the method was positive and appreciated to look back on life in a comprehensive way.

\section{Patient 9}

A single man with a chronic psychiatric disease. $\mathrm{He}$ has experienced several stressful events, which caused a long-term treatment. Today he is, however, a half-time employee. He could see early signs of psychiatric illness in childhood. He thought that this method can give the psychiatric staff a deeper knowledge than otherwise, of the individual patient.

\section{Patient 10}

A married man with sickness benefit because of a chronic psychiatric disease. He has been treated on several occasions. He found it difficult to express his emotions but thought the method was very logical.

\section{Patient 11}

A married and employed woman with children. She has been treated as an inpatient after a stressful event. When we evaluated her life chart, she appreciated going through the life - 'it felt many times like an aha reaction, this is how it was...' 


\section{Discussion}

The time geographic life-charting method activates autobiographic memories using the geographic sites for household moves as anchors. Our findings indicate that only from asking about geographical moves through life, several new events were discovered. A household move could mean an early trauma such as a separation from a parent, or a positive event, such as marriage or a new job. The time geographic life charting also gave us information about the person's social capacity, predisposing, stressful and/or precipitating life events. A stressful event causes different affective reactions, depending on the type of event and point of time when it occurs during life. Thus, the time geographic life chart gave us a comprehensive picture of a person's life history, a holistic perspective, which is useful for psychiatric nursing, evaluation, treatment and care.

The participants were also offered to discuss in their own words, how they perceived the moves and events that they had experienced, and whether they found the time geographic method appropriate. Ten of the 11 participants thought that the time geographic life charting was positive. It could be assumed that the time geographic life charting has a therapeutic value, as it brings forward important situations in a global context. The therapeutic relationship is of great importance for the outcome of care and treatment. Langley \& Klopper (2005) found that trust was described as a prerequisite for a therapeutic relation, and trust takes time to develop. For increased knowledge, a full history of the patient, an understanding of his or her strengths, patterns of coping and support system is needed. Knowledge from a time geographic life chart may improve trust and hence the therapeutic relationship.

The time geographic life chart also offered our conversation a structure because of the chronological procedure and the possibility to penetrate the severity of every event reported by each individual. McLaughlin (1999) found that nurses identified communication skills as being the most important skill in psychiatric nursing, and patients wanted nurses to spend more time with them, helping them with problem-solving. The time geographic life-chart method seems to be a relevant starting point for nursing intervention.

Medical scientists have previously used life charts to illustrate the life situation of psychiatric patients. Osuch et al. (2001) used life charting to illustrate the relationship of life events and treatment interventions with the longitudinal course of illness in patients suffering from posttraumatic stress disorder. They found that longitudinal evaluations are valuable clinical tools for illustrating an individual's symptoms and responses to treatment. They found that their patients varied in their ability to recall events, symptoms and medication from the past, so they had to use old records as an aid to memory. The time geographic life charting uses the geographic sites for household moves as anchors, which probably facilitated their memories. Schärer et al. (2002) made life charts on a palmtop computer, and the first results of a feasibility study were that the patients thought they remembered medication intake, got a better understanding of their illness and participated more actively during the course of illness.

According to Adolf Meyer (Rahe 1990), predisposing events are those that generally occur early in life and might cause vulnerability for different life situations, while precipitating events are those changes in a person's life that occur immediately before an occasion, e.g. an emergency situation on a ward. The time geographic life chart clearly illustrates both predisposing and precipitating events. Our experience is also that this computer-based method makes it easy to make changes or to add different kinds of events of information to the life chart.

Quam \& Abramson (1991) used time lines and life lines with elderly chronically mentally ill adults and found advantages. They thought time and life lines helped the interactive process between them and the client to better insight, understanding and increased integrity. The time geographic life chart seems to support the interaction between staff and patient, explained by Peplau (1952), but more evaluation studies have to be performed to identify applications and properties of this method.

\section{Conclusion}

In our view, the time geographic life chart might be useful in psychiatric care. We regard it as a tool offering a profound understanding of the patients, as it illustrates a comprehensive picture of the patients' life situation. This is a prerequisite for psychiatric nursing striving for good mental health and increased life quality. We also consider the procedure a communication tool between patient and staff.

\section{Acknowledgments}

The authors gratefully acknowledge the respondents for participating in the study. The Swedish Research council no. 14548 , the Scania ALF foundation and Sjöbring Foundation gave financial support. Dr Rolf Wahlström gave a valuable contribution to the intellectual development of the article.

\section{References}

Berg B.L. (1998) Qualitative Research Methods for the Social Sciences, 3rd edn. Allyn and Bacon, Boston. 
Burnard P. (1996) Teaching the analysis of textual data: an experiential approach. Nurse Education Today 16, 278-281.

Conway M.A. \& Bekerian D.A. (1987) Organization in autobiographical memory. Memory and Cognition 15, 119-132.

Ehnvall A. \& Ågren H. (2002) Patterns of sensitisation in the course of affective illness. A life-charting study of treatment-refractory depressed patients. Journal of Affective Disorders 70, 67-75.

Hägerstrand T. (1991) Om tidens vidd och tingens ordning (On the scope of time and order of things). Byggforskningsrådet, BFR T, Stockholm.

Kjellman C. (2003) Ta plats eller få plats? (Summary in English) (Thesis). Institutionen för kulturgeografi och ekonomisk geografi, Lund. rapport 92,7.

Kraepelin E. (1921) Depressive Insanity and Paranoia. E:S Livingstone, Edinburgh.

Langley G.C. \& Klopper H. (2005) Trust as a foundation for the therapeutic intervention for patients with borderline personality disorder. Journal of Psychiatric and Mental Health Nursing 12, 23-32.

Lego S. (1980) The one-to-one nurse-patient relationship. Perspectives in Psychiatric Care 18, 67-89. Reprinted 1999 in Perspectives in Psychiatric Care 35, 4-23.

Lenntorp B. (1992) Biografier, diagnoser och prognoser. I. Självmord som existentiellt problem (Biographies, diagnoses and prognoses). In: Suicide as an Existential-Problem. (ed Beskow, J.), pp. 63-76. The Scientific Board of Folksam, FRN) Folksams vetenskapliga råd. Forskningsrådsnämnden, Stockholm.
McLaughlin C. (1999) An exploration of psychiatric nurses'and patients'opinions regarding in-patient care for suicidal patients. Journal of Advanced Nursing 29, 1042-1051.

Meyer A. (1948) The life-chart. In: The Commonsense Psychiatry of Dr. Adolf Meyer. (ed Lief, A.), pp. 418-422. McGraw-Hill, New York.

Osuch E.A., Brotman M.A., Podell D., et al. (2001) Prospective and Retrospective Life-Charting in Posttraumatic Stress Disorder (The PTSD-LCM): A Pilot Study. Journal of Traum Stress 14, 229-239.

Peplau H.E. (1952) Interpersonal Relations in Nursing: A Conceptual Frame of Reference for Psychodynamic Nursing. Putnam, New York.

Quam J.K. \& Abramson N.S. (1991) The use of time lines and life lines in work with chronically mentally ill people. Health \& Social Work 16, 27-34.

Rahe R.H. (1990) Psychosocial Stressors and Adjustment Disorder: Van Gogh's Life Chart Illustrates Stress and Disease. Journal of Clinical Psychiatry 51 (Suppl.), 13-19.

Roy-Byrne P., Post R., Uhde T.W., et al. (1985) The longitudinal course of recurrent affective illness: life chart data from research patients at the NIMH. Acta psychiatrica Scandinavica 71 (Suppl. 317), pp. 1-34.

Schärer L.O., Hartweg V., Valerius G., et al. (2002) Life charts on a palmtop computer: first results of a feasibility study with an electronic diary for bipolar patients. Bipolar Disorders 4, 107108. 